\title{
Differences in asthma diagnosis and medication use in children living in Germany and the Netherlands
}

\author{
M. Mommers ${ }^{a, c, *}$, G.M.H. Swaen ${ }^{b, c}$, M. Weishoff-Houben ${ }^{a}$, \\ W. Dott $^{\mathrm{a}}$, C.P. van Schayck ${ }^{\mathrm{c}}$
}

a Institute for Hygiene and Environmental Medicine, RWTH Aachen, Pauwelsstraße 30, 52074 Aachen, Germany

b Department of Epidemiology, Care and Public Health Research Institute, Maastricht University, The Netherlands

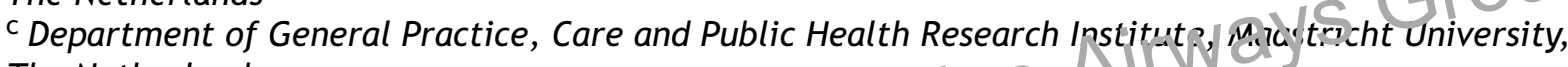
The Netherlands

Received 12 January 2004; accepted 9 kicr ch ?CO.

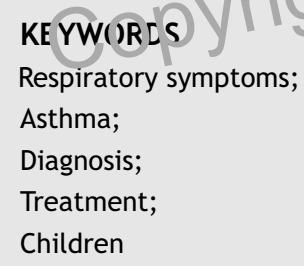

\section{Ai): $\operatorname{tract}$}

Aim: To compare diagnosis and treatment between German and Dutch children with asthmatic symptoms at the age of 5-6 and 7-8 years, and the use of anti-asthma medication at $7-8$ years of age.

Methods: Parents of 4462 children participated in two surveys, in 1995 and 1997. All 465 children identified with current asthmatic symptoms at the age of 5-6 (May 1995 ) or at $7-8$ years of age (May 1997) were sent a third more detailed questionnaire (October 1997).

Results: Asthma diagnosis was more prevalent in Dutch children with current asthmatic complaints (50-60\%), whereas over $90 \%$ of the German children with current asthmatic complaints had been diagnosed with bronchitis. Inhaled $\beta_{2}$-agonists were more frequently used by Dutch children compared to German children $(67.3 \%$ vs. $45.6 \% p<0.01)$ as were inhaled steroids (38.9\% vs. $7.0 \% p<0.01)$. Instead, German children more often used sodium cromoglycate or nedocromil as anti-inflammatory medication as compared with Dutch children $(42.1 \%$ vs. $11.5 \% p<0.01)$.

Conclusions: Differences in diagnosis rates for asthma and bronchitis between German and Dutch children most likely result from differential labelling of complaints, and probably lead to differences in treatment practice, indicating possible undertreatment of German children with inhaled steroids.

(c) 2004 General Practice Airways Group. Published by Elsevier Ltd. All rights reserved.

\footnotetext{
* Corresponding author. Tel.: +49 241 8088520; fax: +49 2418082477.

E-mail address: monique.mommers@post.rwth-aachen.de (M. Mommers).
} 


\section{Introduction}

Asthma is a common disease in childhood with a large social and economic burden. Developed countries might expect to spend an estimated one to two percent of their total health care expenditures on asthma [1]. In children, asthma is an important cause for school absence. School absence in the past year due to asthma was reported for $40-50 \%$ of German and Dutch children [2]. Early diagnosis and appropriate treatment are vital to reduce the burden asthma puts on society and on the individual.

Several national and international guidelines for the diagnosis and management of asthma have been published in recent years [1,3-6]. Current recommendations stress the early introduction of anti-inflammatory agents because asthma is considered a chronic inflammatory disorder. Although some earlier guidelines recommended the use of sodium cromoglycate as maintenance treatment for children with moderate asthma $[3,4]$ more recent guidelines stress the importance of inhaled corticosteroids $[1,5]$. Inhaled steroid use has been shown to improve symptom control and lung function [7] and to reduce the risk of hospital admission [8]. A recent study reported substant at? underuse of preventive therapy, spociti (a); inhaled steroids [9]. The us' $\rho^{\prime}$ in ha ed anti-inflammato medication remain, low even for citic reer Cusing large anounts of inhalec ar anists [10]. A large European survey concluded that the current level of asthma control falls far short of the goals for long-term asthma management as put forward in current guidelines [11].

The incorporation of the guideline recommendations into daily medical practice may depend on factors such as the organisation of health care, health insurance systems, and costs of medical treatment, but probably (and most importantly) it may well depend on doctors' views on asthma diagnosis and management. Many of these factors differ between Germany and the Netherlands, and it is possible that asthma care between German and Dutch children differs likewise. In the Dutch system, general practitioners serve as gate keepers, whereas in Germany patients have open access to physicians or specialists. Moreover, asthma symptom prevalence rates in the Dutch borderland regions were among the highest in the Netherlands [12]; given the lack of information about respiratory health in the adjoining German region, this led the local health authorities to conduct a large Dutch-German study on respiratory health, diagnosis, treatment and risk factors, involving Mu- nicipal Health Services and Universities from both countries. The present study represents the first part of this Dutch-German study, aiming to gain more insight into asthma diagnosis and prescription of anti-asthma medication in German and Dutch children. We investigated whether differences existed in prevalence rates of diagnosis and treatment between Dutch and German children with current asthmatic symptoms. Whereas most studies on asthma control are cross-sectional, our data presented the opportunity to study diagnosis and treatment in the same group of children at different ages. Early recognition of asthmatic symptoms, early diagnosis, and early treatment might prevent disease progression, and willingness to diagnose asthma at an early age might differ between Germany and the Netherlands. Moreover, the design of the study enabled a more accurate assessment of asthmatic status (asthmatic symptoms present on more than one occasion) for studying medication use in these children.

This study therefore compares the prevalence rates of asthma diagnosis and treatment between German and Dutch children wi hat in atic symptoms at the age of 5-6 yev s and again at 7-8 years, and the use anti-astnma medication at $7-8$ years of ago.

\section{Methods}

Respiratory symptoms, diagnosis and treatment were assessed at three different time points in a period of 2.5 years, among children living in the Dutch-German borderland (Figure 1). This region covers the geographic area consisting of the municipal health regions Kreis Heinsberg (Germany), Midden-Limburg and the Westelijke Mijnstreek (The Netherlands). Together, the two Dutch regions have approximately 380,000 inhabitants, while Heinsberg has approximately 250,000 inhabitants.

In May 1995, the parents of all 7201 children living in the study area who were born between November 30th 1989 and December 1st 1990 were invited to complete a questionnaire that included the WHO questions about respiratory symptoms [13] and questions about allergies, diagnosis and treatment. Parents of 5692 children $(79.0 \%)$, who turned 5-6 years in the study year, participated in 1995. In spring 1997, it was possible to trace 5459 of these children for participation in the second survey, using the same parental questionnaire; the remaining 233 children had moved out of the study area or their forwarding address was unknown.

We studied differences in diagnosis and treatment rates among German and Dutch children with 


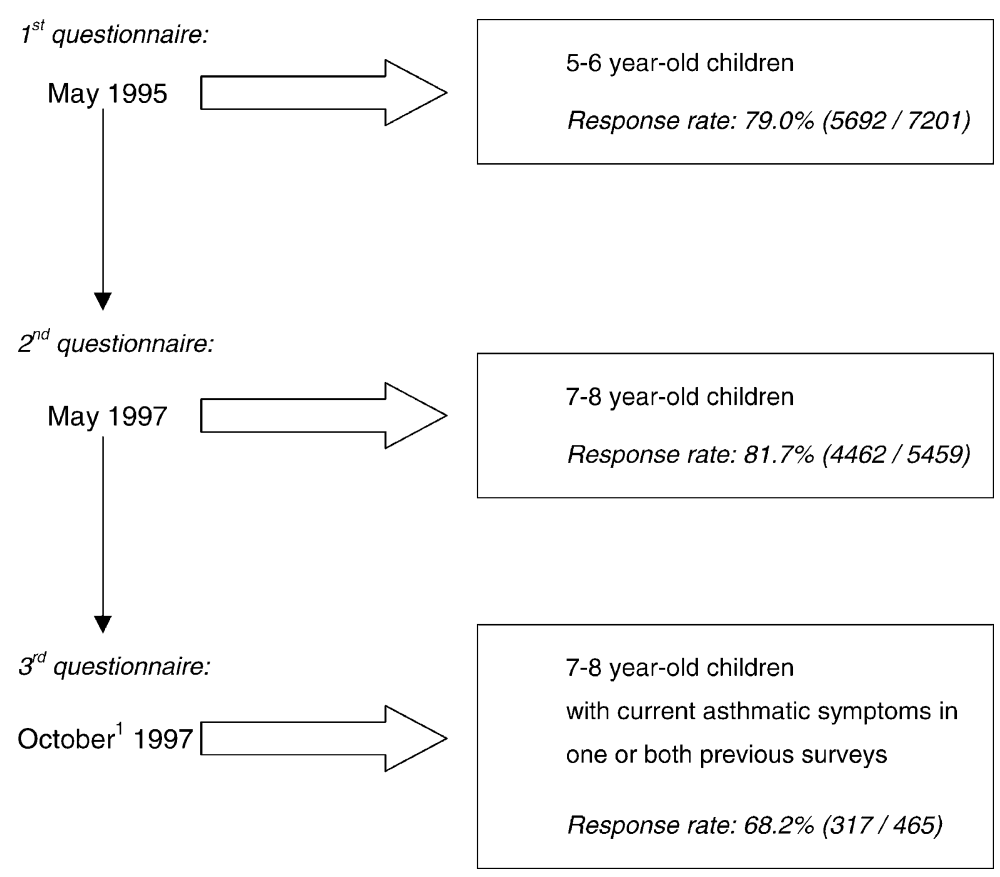

Figure 1 Response rates of the different parts of the study ${ }^{1}$ (from September 29 th to November 7 th).

reported current asthmatic symptoms. Current asthmatic symptoms were defined as reported wheezing and attacks of shortness of breiti with wheezing in the respective vear preceding the surveys of 1995 and 1997 Fon the purpose of defining currelo asthmatic symptoms in the present study ye used whit setolur knowledge, an unvalidated definition. Although our definition of current asthmatic symptoms - positive response to both questions about wheezing and shortness of breath with wheezing in the past 12 months had not been validated in this combination, each question separately has been found to have both high sensitivity and specificity in relation to clinical asthma [14]. In all, 465 children had current asthmatic symptoms either at 5-6 years of age (in May 1995) or at 7-8 years of age (in May 1997), or at both ages. In October (from September 29th to November 7th) 1997, the parents of these 465 children were asked to complete a third, more detailed questionnaire, which included ISAAC questions on occurrence and severity of wheezing [15] (different questions regarding wheezing or whistling in the child's chest, number of attacks of wheezing, sleep disturbance due to wheezing and wheezing severe enough to limit the child's speech to only one or two words at a time between breaths) and management (questions regarding medication use (tablets, sprays etc.) against wheezing or asthma in the last 12 months, number of visits to a general practitioner, pulmonologist, paediatrician or hospital emergency department for a regular check up or acute attach bi Wheesing or asthma in the last 12 .nonths), as well as questions on ir do mivironment. Questionnaires were checked for completines s) Nan assistant of the Municipal Viealin bervice in the presence of one or both parents. Because of the time frame of the study (from May 1995 through to October 1997) for some children current asthmatic symptoms had only been reported in 1995, whereas for others current asthmatic symptoms had been reported in May 1997. For the purpose of describing medication use in the past 12 months in children with current symptoms, we used the question 'Has your child had wheezing or whistling in the chest in the last 12 months?' from the third, more detailed questionnaire to identify children with current symptoms in October 1997.

The study was approved by the medical ethics committee of the "Ärztekammer Nordrhein" in Germany.

\section{Statistical analysis}

Prevalence rates were calculated by dividing the number of positive responses to each question by the total number of responses to that question. Data are presented stratified by country and age group. Chi-square tests were used to analyse differences in prevalence rates between the two countries. Fisher's exact test was used when the expected frequency of any cell was less than 5 . 


\section{Results}

\section{Response rates}

The overall response rates of the study are outlined in Figure 1. In 1997, 1402 (74.8\%) German and 3060 (85.4\%) Dutch participants of the 1995 survey took part in the second survey. The proportion of boys was slightly larger in the German compared to the Dutch region: $52.9 \%$ versus $51.0 \%$ respectively.

Of the 4462 children participating in both surveys, 341 children $(7.6 \%)$ had current asthmatic symptoms at the age of 5-6 years (in 1995) and 240 (5.4\%) had current asthmatic symptoms at the age of 7-8 (in 1997); 465 children had current symptoms either at 5-6 years of age or at 7-8 years of age, or at both ages. The additional questionnaire was completed for $68.2 \%(317 / 465)$ of these children, showing minimal differences in response rates between German (67.7\%) and Dutch children (68.4\%). Again, the proportion of German boys $(68.5 \%)$ was slightly larger than for Dutch boys (64.6\%).

\section{Diagnosis rates in German and Dutch children with current asthmatic symptoms}

Among 5-6 year-olds with carrencaininatic symptoms, proportionatiy nicre nitcrin than Germarcicil dren were diagnosed with asthma (Table 1). Two years later, this difference was still present but somewhat smaller: $59.7 \%$ for Dutch and $37.2 \%$ for German children $(p<0.01)$. Among $7-8$ year-old children diagnosed with asthma, $77.3 \%$ of the Dutch children and $31.0 \%$ of the German children already had an asthma diagnosis at the age of 5-6 ( $p<$ 0.01 ). Bronchitis was diagnosed in more than $90 \%$ of the German children with current asthmatic complaints (Table 1). On the other hand, more than 40\% of the German children without any reported respiratory symptom at 5-6 years of age as well as at 7-8 years of age, were also reported to have ever been diagnosed with bronchitis.

Allergies were diagnosed more often in Dutch compared to German children with asthmatic complaints, especially at the age of 5-6 years (Table 1).

\section{Anti-asthma medication use in German and Dutch children with current asthmatic symptoms}

We identified 175 children with. cirrent asthmatic symptoms at the chid ssessment of the study fo de-Crib.ng severity of symptoms (Table 2) and anti-asthin ine Gi-ation use in the past year (Table (3). Whe zing attacks were more frequently lepurted for Dutch children, whereas speechGopy Reproaun

Table 1 Prevalence of diagnosis and treatment for asthma, bronchitis and allergies in children with current asthmatic symptoms at different ages by country.

\begin{tabular}{|c|c|c|c|c|c|c|}
\hline & \multicolumn{3}{|c|}{$5-6$ year-olds $(n=341)$} & \multicolumn{3}{|c|}{$7-8$ year-olds $(n=240)$} \\
\hline & German \% (n) & Dutch\% $(n)$ & $p$-value & German\% ( $n)$ & Dutch\% $(n)$ & $p$-value \\
\hline $\begin{array}{l}\text { Physician-diagnosed } \\
\text { asthma (lifetime) }\end{array}$ & $21.2(21)$ & $52.2(117)$ & $<0.01$ & $37.2(32)$ & 59.7 (89) & $<0.01$ \\
\hline $\begin{array}{l}\text { Physician-diagnosed } \\
\text { bronchitis (lifetime) }\end{array}$ & 95.2 (99) & $65.7(151)$ & $<0.01$ & $93.3(83)$ & $56.5(83)$ & $<0.01$ \\
\hline $\begin{array}{l}\text { Physician-diagnosed } \\
\text { allergies (all): }\end{array}$ & $37.6(38)$ & $54.2(128)$ & 0.01 & $57.3(47)$ & $65.5(93)$ & 0.22 \\
\hline House dust mite allergy & $18.0(16)$ & $32.5(68)$ & 0.01 & $40.3(27)$ & $52.5(64)$ & 0.11 \\
\hline Grass/pollen allergy & $19.3(17)$ & $24.0(48)$ & 0.38 & $48.7(37)$ & $45.0(49)$ & 0.62 \\
\hline Cow's milk allergy & $5.9(5)$ & $23.4(47)$ & $<0.01$ & $3.5(2)$ & $26.0(27)$ & $<0.01$ \\
\hline Chicken egg allergy & $4.8(4)$ & $10.9(21)$ & 0.10 & $3.6(2)$ & $20.2(21)$ & $<0.01$ \\
\hline Mould allergy & $4.8(4)$ & $5.9(11)$ & 1.00 & $19.0(11)$ & $10.3(9)$ & 0.14 \\
\hline Pet allergy & $17.2(15)$ & $32.0(66)$ & 0.01 & $34.3(23)$ & $47.1(57)$ & 0.09 \\
\hline Other allergies & $14.9(13)$ & $23.9(47)$ & 0.09 & $36.4(24)$ & $34.7(33)$ & 0.83 \\
\hline $\begin{array}{l}\text { Treatment (by a specialist) } \\
\text { for asthma in the past } 12 \\
\text { months }\end{array}$ & 19.4 (19) & $27.5(61)$ & 0.12 & $29.8(25)$ & $30.2(45)$ & 0.94 \\
\hline $\begin{array}{l}\text { Treatment (by a specialist) } \\
\text { for bronchitis in the past } \\
12 \text { months }\end{array}$ & $89.4(93)$ & $27.0(61)$ & $<0.01$ & $78.2(68)$ & $19.2(28)$ & $<0.01$ \\
\hline
\end{tabular}


Table 2 Frequency of wheezing attacks, sleep disturbance due to wheeze and speech limiting wheeze in the past year in children with current asthmatic symptoms by country.

\begin{tabular}{llll}
\hline & \multicolumn{3}{l}{$7-8$ year-old children with asthmatic complaints $(n=175)$} \\
\cline { 2 - 4 } & German\% $(n)$ & Dutch\% $(n)$ & $p$-value \\
\hline Wheezing attacks $(\geq 1)$ & $89.7(52)$ & $97.4(114)$ & 0.06 \\
Sleep disturbance due to wheeze & $60.0(33)$ & $68.4(78)$ & 0.28 \\
Speech limiting wheeze & $36.8(21)$ & $21.9(25)$ & 0.04 \\
\hline
\end{tabular}

limiting wheeze was more prevalent in German children with current asthmatic symptoms (Table 2).

Overall, for $80 \%$ of the 7-8 year-old German and Dutch children with current asthmatic symptoms, any medication use for their complaints in the past 12 months was reported (Table 3 ). Antiasthma medication, as listed in Table 3 , had been used by $63.8 \%$ of the German children and by $72.6 \%$ of the Dutch children. Inhaled $\beta_{2}$-agonists were used by more of the Dutch children compared to German children as were inhaled steroids. Instead, German children more often used sodium cromoglycate or nedocromil as anti-inflammatory medication compared with Dutch children. Inhaled $\beta_{2}$-agonists were used by $15.8 \%$ of the German children and by $26.5 \%$ of the Dutch children as monotherapy (Table 4). In combination with in naled $\beta_{2}$-agonists German children most fre 10 G $n$ cly used sodium cromoglyeate for nedociomil, whereas it Dutcinchilc'ren in haled $\beta_{2}$-agonists vere nd ief frequently combined with inhlited sterolds.

\section{Discussion}

The results of the present study show differences between German and Dutch asthmatic chil- dren with respect to diagnosis and treatment. Almost all German children had been diagnosed with bronchitis. Asthma diagnosis was more frequent in Dutch than in German children. Inhaled $\beta_{2}$-agonists and inhaled steroids were more frequently used by Dutch children, whereas more German children used inhaled sodium cromoglycate or nedocromil.

\section{Diagnosis rates differ between German and Dutch children with current asthmatic symptoms}

The large difference in diag(ii) sis rates by country probab!y criginated irom differential labelling nCespiratury symptoms. German physicians may have preferrad t $t \in$ abek Dronchitis because (in the parent: (vicw) it is a less threatening and stigmatising diagnosis than asthma. In Germany the label bronchitis includes respiratory symptoms ranging from mild coughing symptoms to more severe asthmatic symptoms. In line with this, the variation in prevalence rates for allergy diagnoses by country might well reflect differences in diagnostics rather than a real difference in atopic predisposition.

Table 3 Medical care use in the past year in children with current asthmatic symptoms by country.

\begin{tabular}{lccc}
\hline & \multicolumn{3}{l}{$7-8$ year-old children with asthmatic complaints $(n=175)$} \\
\cline { 2 - 4 } & German\% $(n)$ & Dutch\% $(n)$ & \multicolumn{1}{c}{$p$-value } \\
\hline Medication use in the past 12 months & $80.7(46)$ & $80.0(92)$ & 0.91 \\
Inhaled $\beta_{2}$-agonists & $45.6(26)$ & $67.3(76)$ & $<0.01$ \\
Inhaled anticholinergic agents & $3.5(2)$ & $6.2(7)$ & 0.72 \\
Inhaled steroids & $7.0(4)$ & $38.9(44)$ & $<0.01$ \\
Sodium cromoglycate/nedocromil & $42.1(24)$ & $11.5(13)$ & $<0.01$ \\
Oral $\beta_{2}$-agonists & $8.8(5)$ & - & $<0.01$ \\
Theophylline & $1.8(1)$ & - & 0.34 \\
Ketotifen & $5.3(3)$ & - & 0.04 \\
Corticosteroids (oral) & $7.0(4)$ & $0.9(1)$ & 0.04 \\
Corticosteroids (rectal) & $17.5(10)$ & - & $<0.01$ \\
Physician's visit for acute asthmatic & $84.9(45)$ & $72.5(79)$ & 0.08 \\
$\quad$ problems in the past 12 months & & & \\
Physician's visit for a regular & $38.3(18)$ & $49.1(52)$ & 0.22 \\
$\quad$ check-up in the past 12 months & & & \\
\hline
\end{tabular}


Table 4 Percentage of German and Dutch children with current asthmatic symptoms using $\beta_{2}$-agonists as monotherapy or in combination with anti-inflammatory medication.

\begin{tabular}{llrr}
\hline & \multicolumn{3}{l}{$7-8$ year-old children with asthmatic } \\
\cline { 2 - 4 } complaints $(n=175)$ & & \\
\cline { 2 - 4 } & German\% $(n)$ & Dutch\% $(n)$ & $p$-value \\
\hline$\beta_{2}$-agonists as monotherapy & $15.8(9)$ & $26.5(30)$ & 0.12 \\
$\beta_{2}$-agonists with inhaled steroids & $1.8(1)$ & $33.6(38)$ & $<0.01$ \\
$\beta_{2}$-agonists with sodium cromoglycate/nedocromil & $26.3(15)$ & $6.2(7)$ & $<0.01$ \\
$\beta_{2}$-agonists with inhaled steroids and sodium & $1.8(1)$ & $0.9(1)$ & 1.00 \\
cromoglycate/nedocromil & & & \\
\hline
\end{tabular}

\section{Therapeutic regimes differ between German and Dutch children with current asthmatic symptoms}

Fewer German than Dutch children with current asthmatic symptoms reported the use of antiasthma medication in the past year. The rate of anti-asthma medication use in German children (64\%) was similar to the rate previously reported for German children [16]. Most guidelines recommend the use of $\beta_{2}$-agonists in children with mild asthma [3-6]. Our results indicate that $\beta_{2}$-agonists were used more frequently in Dutch children than in German children. Also, proportionally more Dutch ¿itar, German children used $\beta_{2}$-agonists as monet pelapy. It is possible that Dutch hys ocn: adnered more strictly to the guifelines and prescribed of? do onists to chi d en with mild internigent astrimatic symptoms (step one in the GINA guidelines [1]). Another explanation could be that among Dutch children mild asthmatic symptoms are more prevalent than among German children, or that parents of Dutch children more readily report their child's complaints to a physician. The latter is less likely because underpresentation of respiratory symptoms to the general practitioner is a large problem among Dutch adult asthmatic patients [17].

In addition, more of the Dutch children used inhaled steroids as maintenance treatment, whereas most German children in this study used sodium cromoglycate or nedocromil. Our results are consistent with recent reports of lower use of inhaled steroids in Germany $[16,18]$ and in other countries $[2,9]$. Low steroid use in German children may have resulted from parents' or physicians' fear of side effects of treatment with steroids, or from different recommendations in national guidelines. For instance, the 1998 German national guidelines [6] recommend the use of sodium cromoglycate as an alternative to inhaled steroids in children with mild asthma whereas the 1998 Dutch guidelines recommend inhaled steroids as the prophylactic treatment of first choice [5]. The use of steroids largely depends on the degree of asthma severity. As our definition of asthmatic symptoms was based solely on questionnaire reports and did not include more objective clinical diagnostic methods, it was not possible to determine accurately the severity of the asthmatic symptoms. It is therefore possible that most of the children in this study only had mild complaints not requiring treatment with steroids. We studied medication use among children who had had at least two periods of wheezing or attacks of shortness of breath with wheezing a $\mathrm{CV}$ ' d ffferent time points. In about holf binese children asthma had been dian posed.

C Acequate treatment hay have affected the frequency and ir pored tine severity of symptoms in the'se chiciren. We have no information on treatment compliance: low compliance has been reported worldwide and is, on average, not strongly influenced by disease severity [19]. In children with asthma, adherence rates to prescribed treatment regiments are often below 50\% [20].

\section{Possible limitations of the study}

We cannot address a possible responder bias because we have no information on the children who did not participate in both 1995 and 1997. Possibly parents of children with symptoms were more likely to participate than parents of children without symptoms, leading to overrepresentation of symptomatic children in our study. In line with this, children with asthmatic symptoms whose parents had completed the third, more detailed questionnaire were more frequently found to have reported symptoms in the second survey (in 1997) than nonparticipants for the third questionnaire. Since we only selected children with current asthmatic symptoms for the analysis of treatment, this differential response probably did not influence the main outcomes of this study. However, based on our data, we cannot irrefutably exclude a real difference in prevalence of asthmatic symptoms between the 
two countries but it seems likely that different diagnostic labelling plays a major role in explaining these data.

\section{Conclusions}

The study results show differences in diagnostic labelling of asthmatic symptoms between countries, possibly leading to the observed differences in asthma management. In Dutch children asthmatic symptoms were more often labelled as asthma, whereas in German children they were more often labelled as bronchitis. Although this did not result in large differences in prevalence of overall antiasthma medication use between German and Dutch children living in the study area, differences in the use of specific anti-asthma medication were found. Most Dutch children used inhaled steroids as antiinflammatory treatment, whereas only a minority of German children used inhaled steroids. Most German children were treated with sodium cromoglycate or nedocromil, possibly indicating undertreatment of German children with steroids. It seems feasible that German physicians have to overcome their reluctance to diagnose children with asthma symptoms as having asthma, in order to increase the use of inhaled corticosteroids as the most $i p$ propriate treatment in respect io thelnderlying pathophysiology of thi indisease.

\section{Acknowledgement}

The authors wish to thank Ron Derkx, Gonnie Jongmans-Liedekerken, Paul Mertens and Bernd Ziemer for their cooperation in the study. The study was financially supported by the European Union, the Euregio Maas-Rhine (Interreg II project EMR.INT2.96.09.V.039), the Land Northrhine-Westphalia, the Province of Limburg and the counties of Heinsberg, Midden-Limburg and Westelijke Mijnstreek.

\section{References}

[1] Global Initiative for Asthma (GINA). Global strategy for asthma management and prevention. National Institutes of Health, National Heart, Lung, and Blood Institute. NIH Publication No. 02-3659, Revised 2002.

[2] Vermeire PA, Rabe KF, Soriano JB, Maier WC. Asthma control and differences in management practices across seven European countries. Respir Med 2002;96: 142-9.

[3] National Heart, Lung and Blood Institute. International consensus report on diagnosis and treatment of asthma. Eur Respir J 1992;5:601-41.

[4] Asthma: a follow up statement from an international paediatric asthma consensus group. Arch Dis Child 1992;67:240-8.

[5] Dirksen WJ, Geijer RM, de Haan M, de Koning G, Flikweert $\mathrm{S}$, Kolnaar BG. NHG-Standaard astma bij kinderen (eerste herziening). Huisarts Wet 1998;41:130-43.

[6] Wettengel R, Berdel D, Hofmann D, et al. Empfehlungen zur Asthmatherapie bei Kindern und Erwachsenen. Pneumologie 1998;52:591-601.

[7] Price J. The role of inhaled corticosteroids in children with asthma. Arch Dis Child 2000;82 (suppl 2):II10-14.

[8] Blais L, Suissa S, Boivin JF, Ernst P. First treatment with inhaled corticosteroids and the prevention of admissions to hospital for asthma. Thorax 1998;53:1025-9.

[9] Warman KL, Silver EJ, Stein RE. Asthma symptoms, morbidity, and antiinflammatory use in inner-city children. Pediatrics 2001;108:277-82.

[10] Goodman DC, Lozano P, Stukel TA, Chang CH, Hecht J. Has asthma medication use in children become more frequent, more appropriate, or both? Pediatrics 1999;104:187-94.

[11] Rabe KF, Vermeire PA, Soriano JB, Maier WC. Clinical management of asthma in 1999: the Asthma Insights and Reality in Europe (AIRE) study. Eur Respir J 2000:16:802- 7 .

[12] van der Wal MF, Uitenbroek DG Verr oefi AF. Joegen omen percentage bosisschoc $\vee$ ind ren met astmatische klachten in Nede-1anc 9:3/8;-1994-55; een literatuuronderzoek. I I Ed Tijuschr Geneeskd 2000 144:1780-5.

[13] Florey C cuV 'Ee Her SP. W. Wethods for Cohort Studies of Criin il A iflc V Limitation. WHO Regional Publications Eurc pean Series No. 12. London, United Kingdom, 1982.

[14] Remes ST, Pekkanen J, Remes K, Salonen RO, Korppi $M$. In search of childhood asthma: questionnaire, tests of bronchial hyperresponsiveness, and clinical evaluation. Thorax 2002;57:120-6.

[15] Asher MI, Keil U, Anderson HR, et al. International Study of Asthma and Allergies in Childhood (ISAAC): rationale and methods. Eur Respir J 1995;8:483-91.

[16] Beimfohr C, Maziak W, von Mutius E, et al. The use of anti-asthmatic drugs in children: results of a communitybased survey in Germany. Pharmacoepidemiol Drug Saf 2001;10:315-21.

[17] van Schayck CP, van der Heijden FM, van den Boom G, Tirimanna PR, van Herwaarden CL. Underdiagnosis of asthma: is the doctor or the patient to blame? The DIMCA project. Thorax 2000;55:562-5.

[18] Lagerlov P, Veninga CC, Muskova M, et al. Asthma management in five European countries: doctors' knowledge, attitudes and prescribing behaviour. Drug Education Project (DEP) group. Eur Respir J 2000;15:25-9.

[19] Cerveri I, Locatelli F, Zoia MC, Corsico A, Accordini S, de Marco R. International variations in asthma treatment compliance: the results of the European Community Respiratory Health Survey (ECRHS). Eur Respir J 1999;14:288-94.

[20] Bender BG. Overcoming barriers to nonadherence in asthma treatment. J Allergy Clin Immunol 2002;109:S554-9.

Available online at www.sciencedirect.com Science 0 Direct 